\title{
A Case Study of Li Bai’s Poems from Cognitive Metonymic Perspective
}

\author{
Wei $\mathrm{Li}^{1} \&$ Huijun Tang ${ }^{2}$ \\ ${ }^{1}$ College of International Studies, Southwest University, Chongqing, China \\ ${ }^{2}$ College of Foreign Languages and Culture, Chengdu University, Chengdu, China \\ Correspondence: Wei Li, College of International Studies, Southwest University, Chongqing, China. E-mail: \\ rowomansky@yahoo.com
}

Received: November 26, 2018 Accepted: January 3, 2019 Online Published: February 24, 2019

doi:10.5539/ijel.v9n2p237

URL: https://doi.org/10.5539/ijel.v9n2p237

\begin{abstract}
Metonymy has long been treated as the forgotten trope while cognitive approach to metonymy sheds new light on the research of metonymy. Metonymy is not only considered as a figure of speech, but also a cognitive process in which one conceptual entity, the vehicle, provides mental access to another conceptual entity, the target, within the same idealized cognitive model (Radden \& Kovecses, 1999). The investigation of concrete metonymy in Li Bai's poems is aimed to offer a new perspective of metonymic devices for literary studies. Metonymy has the capacity to generate impressive aesthetic effects and highlight the theme in poetry. What's more, it is a mirror to reflect the cognitive process the poet construes and thinks about the world. As far as readers are concerned, their interpretation of poetry partly depends on their mental construction of metonymic devices.
\end{abstract}

Keywords: metonymy, reference point, Li Bai's poems

\section{Introduction}

The exploration of metonymy can be dated back to ancient Greek eras. The Greek grammarian Trypho (Trop.

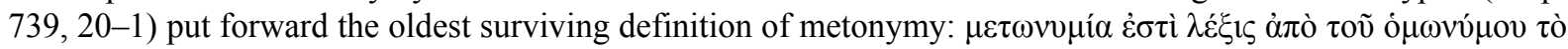
$\sigma 0 v \tilde{v} v 0 \mu \mathrm{ov} \delta \eta \lambda$ oṽ $\alpha$, which indicates that metonymy is an expression that explains a synonym by a homonym. As a matter of fact, metonymy has long been looked upon as a variant of metaphor and thus received little attention compared with the attention that has been lavished on metaphor. Therefore metonymy may be called "the forgotten trope".

In his paper "The Metaphoric and Metonymic Poles"(1956), Roman Jakobson treated the metaphoric and metonymic poles as the two basic ways of thought reflected in general human behavior and in language. It is Roman Jakobson who was the first to pay equal attention to metaphor and metonymy. In his view, metonymy is not the variant of metaphor, but a radically different opposite. Later Lakoff and Johnson launched the metaphor revolution by their book known as Metaphors We Live by (1980), but it still took almost another twenty years to fully redress the balance between metaphor and metonymy, culminating in Panther \& Radden's Metonymy in Language and Thought (1999) and Barcelona's Metaphor and Metonymy at the Crossroads (2003). Lakoff and Johnson claim that "like metaphors, metonymic concepts structure not just our language but our thoughts, attitudes and actions" (Lakoff \& Johnson, 1980, p. 9). Later Radden and Kovecses (1999, p. 21) define metonymy as follows:

metonymy is a cognitive process in which one conceptual entity, the vehicle, provides mental access to another conceptual entity, the target, within the same idealized cognitive model.

Here we adopt the view that metonymy is not a variant of metaphor, and metonymy is not only a figure of speech but also a basic way of thinking in which the vehicle offers mental access to the target.

Metonymy plays a significant role in our daily life. Metonymy is pervasive because on the one hand it is not probable for us to trigger all the knowledge in our brain for a certain topic immediately, and on the other hand it is not likely for us to express every aspect of our intended meaning in the language we use. Consequently, mentally we are inclined to think metonymically; in other words, we usually turn to a prominent part of a concept, and use that salient aspect as a mental access to the whole concept. Furthermore, the incapability of 
covering every aspect of our intended meaning by our language calls for inferences to make clear what is meant, and metonymy serves as a very important medium. G. Esnault $(1925$, p. 31) sums up the compressed allusive character of metonymy like this: "Metonymy does not open new paths like metaphorical intuition, but, taking too familiar paths in its stride, it shortens distances so as to facilitate the swift intuition of things already known."

\section{Metonymy in Poetry}

Rosch (1975, pp. 532-547) first put forward that human beings are endowed with the reference point capacity, which is the ability to gain mental contact with a target concept via a vehicle concept which serves as a reference point. Later Langacker (1993) introduced reference point theory into analysis of metonymy. Langacker (1993, p. 30) believes that metonymy is basically a reference-point phenomenon... affording mental access to the desired target.

The metonymic way of thinking is pervasive in poetry and literature. Poetic language has long been a focus of literary explorations. The ancient Chinese poets created a variety of images and conferred upon them certain symbolic meanings. Poetry is not mechanic description of history, but a vivid reflection of how people in those days expressed their feelings, hopes and dreams. What's more, poetry can help us unfold the exceptional attributes of a person, a culture, and even an age. Metonymy, as a poetic thought, is something that pertains to poetry and literature. By means of metonymy, the poet can convey his feelings and aspirations in an artistic and novel way. With the help of metonymy, it is possible to express complex meanings with fewer words. On the other hand, metonymy can facilitate people's understanding of an event from a very salient respect, which triggers people's interest in the whole event and helps people associate this salient respect with other respects of the event. The texts chosen for evaluation and analysis in the process of conducting the research for this paper were taken from ancient Chinese poetry, Li Bai's poems, due to their exceptional richness in poetic imagery and themes. The following part will focus on exploring metonymy and cognitive construction in Li Bai's poems.

\section{Metonymy in Li Bai's Poems}

Tang Dynasty (618-907AD) is the most glistening historical period in China's history. In this glorious period, the economy, politics, culture and military strength reached an unprecedented advanced level. As we all know, the most glorious cultural achievement in Tang Dynasty was the distinguished Tang Poems. Themes of Tang Poems were various, ranging from life in the frontiers, life in peaceful fields, historical affairs and imaginative fancies. The literary level of Tang Poems reached a peak that had never been surpassed in the history of Chinese literature. Li Bai (AD 701-762) is one of the prominent figures in the flourishing of Chinese poetry in Tang Dynasty. As a poet of high prestige, he brought traditional poetic forms to new heights. The themes of his poems range from friendship, aspirations, rapt with wine and moon, nostalgia, sympathy for the common folks to antipathy towards needless wars etc.

Li Bai's poems act as a mirror, which reflects much of his own life, such as places he visited, his own dreams, friends whom he bid farewell to and so on, and also demonstrates the social reality and spirit of Tang Dynasty. In his poems, metonymy functions as a powerful device to embody his feelings and values. Consequently, the readers' understanding of the poems also hinge on their interpretation of metonymy in the poems. For example, Li Bai was passionate about fame and honor and he never attempted to hide his political ambitions. But at the same time his proud and unyielding temperament prevented him from being subservient and servile to the nobles and the privilege. He, though a common person himself, tried to communicate with the nobles on the equal basis. Correspondingly, his belief is reflected in his poems partly with the help of metonymy. In this case, poetic metonymy serves as a reference point, which triggers readers' association between the metonymic source and metonymic target, thus takes great effect in expressing the poet's rich feelings with a few lines. The following part is concerned with the analysis of construction and functions of HISTORICAL ALLUSIONS FOR CURRENT EVENTS METONYMIES in Li Bai's poems.

\subsection{Analysis of Li Bai's Yearning for Fame and Success from Cognitive Metonymic Perspective}

Jade Pot Song was written in the fall, 743 AD during Li Bai's tenure as a member of the Imperial Academy. The following is the first two lines of this poem.

烈士击玉壶,

壮心惜暮年。(《玉壸吟》)

Lie shi ji yu hu,

Zhuang xin xi mu nian. (Yu Hu Yin)

The warrior strikes the jade pot, singing a lament 
For ambition and old age.

The title, Jade Pot Song, together with the first two lines of the poem, can be dated back to the story of General Wang Dun in Eastern Jin Dynasty. It is said that every time after General Wang Dun drank wine, he would strike the spittoon, singing a lament for his ambition and old age. This lament originates from a poem written by Cao Cao, which starts with "An old steed in the stable still aspires to gallop a thousand li, and an old hero still cherishes high aspirations." The title collaborates with the first two lines in activating mental access to the poet's mixed emotions and striking a chord with the poet. His yearning to achieve success in the political arena ended with the disappointment, yet he still held hope for his aspirations.

\author{
世人不识东方朔, \\ 大隐金门是谪仙。 \\ 西施宜笑复宜頻, \\ 丑女效之徒累身。(《玉壶吟》) \\ Shi ren bu shi dong fang shuo, \\ Da yin jin men shi zhe xian. \\ $\mathrm{Xi}$ shi yi xiao fu yi pin, \\ Chou nu xiao zhi tu lei shen. (Yu Hu Yin)
}

The world does not know Dongfang Shuo,

The banished immortal in the court.

Xi Shi looks beautiful no matter whether she smiles or frowns,

But Dong Shi's clumsy imitation makes herself more annoying.

Dongfang Shuo was a great talent during the reign of Han Wudi. Unfortunately, Han Wudi treated him as a court jester, which made him unsatisfied and indignant. Most of the courtiers thought that Dongfang Shuo was mad. He once said that people in the past lived in seclusion in mountains while people like him chose to live in seclusion in court. The ingenious use of this historical allusion serves as a reference point to provide mental access to Li Bai's plight and shortens distances in order to facilitate the prompt identification of things known about the poet himself. Emperor Xuanzong of Tang didn't think highly of Li Bai and took him as a court jester to amuse the nobles in the banquets. Li Bai's talent in assisting the emperor to govern the country was ignored entirely. He was trapped the same dilemma like Dongfang Shuo, living in seclusion in the court as a banished immortal, which was quite pathetic in contrast to his great talents. The historical allusion of Dongfang Shuo is used to highlight the poets' depression and deep resignation.

The next two lines stem from another historical allusion about Xi Shi, who was one of the renowned Four Beauties of ancient China. She was said to have lived during the end of Spring and Autumn period in Zhuji, the capital of the ancient State of Yue. She was exceedingly beautiful so that when she leaned over a balcony to look at the fish in the pond, the fish would be so dazzled that they forgot to swim and sank below the surface. Xi Shi suffered from heartache, so she put her hand on the chest and knitted her brows, which made her more captivating. Unlike Xi Shi, the girl next-door, called Dong Shi was very ugly, but she enjoyed imitating Xi Shi by putting her hand on the chest and knitting her brows, which made her much uglier and more annoying. Li Bai likened himself to Xi Shi. To be more specific, his intrinsic virtues and temperament were compared to Xi Shi's natural beauty. Any attempt to imitate his style turned out to be a failure, just like Dong Shi's clumsy imitation. No matter what kind of situations he confronted, he would remain unruffled and take them calmly. This metonymy of Xi Shi and Dong Shi helps portray the poet's pride and confidence in a vivid and impressive way.

Another poem, Hard is the Way of the World (I), is also abundant with historical allusions.

闲来垂钓碧溪上,

忽复乘舟梦日边。

行路难! 


\section{行路难!}

多歧路,

今安在?

长风破浪会有时,

直挂云帆济沧海。(《行路难》其一)

Xian lai chui diao bi xi shang,

Hu fu cheng zhou meng ri bian.

Xing lu nan!

Xing lu nan!

Duo qi lu,

Jin an zai?

Chang feng po lang hui you shi,

Zhi gua yun fan ji cang hai. (Xing Lu Nan, Qi Yi)

I can but poise a fishing pole beside a stream

Or set sail for the sun like a sage in a dream.

Hard is the way,

Hard is the way.

Don't astray!

Wither today?

A time will come to ride the wind and cleave the waves,

I'll set my cloud-white sail and cross the sea which raves. (Xu, 2014, p. 53)

The first two lines contain two historical stories about two strategists in ancient China, Jiang Ziya and Yi Yin. "I can but poise a fishing pole beside a stream", functions as a reference point to activate the readers' encyclopedic knowledge about Jiang Ziya, who was an expert in military affairs and hoped that someday someone would call on him to help overthrow King Zhou. He waited placidly, fishing in a tributary of the Wei River, using a barbless hook or even no hook at all, on the theory that the fish would come to him of their own volition when they were ready. This strange way of fishing spread quickly and was reported to Ji Chang. Ji Chang sent his soldier and official to invite Jiang Ziya, but in vain. Realizing that Jiang was an unusual old man, Ji Chang went to invite Jiang himself and had a conversation with him. He discovered that this grey-haired fisherman was actually an astute political thinker and military strategist. Jiang saw his sincerity and agreed to work for him, and later helped Ji Chang and his son overthrow Shang Dynasty and establish Zhou Dynasty. Thus Ji Chang became King Wen of Zhou Dynasty.

"Or set sail for the sun like a sage in a dream" indicates another historical allusion, which is concerned with Yi Yin, a minister of the early Shang Dynasty and one of the honored officials of the era. He helped Tang of Shang defeat King Jie of Xia and establish Shang Dynasty. It is said that before Yi Yin met Tang of Shang, he had a dream that he set sail for the sun and the moon, which symbolize the monarch in ancient Chinese culture.

With the help of these two historical allusion metonymies, through just a few words, Li Bai can give voice to his frustration, and in the meanwhile his expectations to be appreciated by a sagacious and open-minded monarch. He still had the desire to make contributions to the country and achieve success and fame like Jiang Ziya and Yi Yin.

The last line but one, "A time will come to ride the wind and cleave the waves", suggests another historical allusion. Zong Que, a brave man with great resourcefulness, was a famous general in Kingdom of Song in Southern Dynasty. According to the Book of Song, when Song Que was in his boyhood, his uncle, Zong Bing asked about his aspirations. Zong Que responded in a metaphorical way: "I would like to ride the wind and cleave the waves." From then on, riding the wind and cleaving the waves has been popularly used as a metaphor to indicate achieving political ambition. Here the application of this historical story activates the readers' 
background knowledge of Zong Que, his bravery and military genius, and at the same time, strengthens the poet's expression of his strong will to achieve his political ideal in spite of a great many obstacles. What's more, the cluster of the historical allusion metonymies in the same poem collaborate on the implied conveyance of the poet's complex emotions: his upset, expectation and aspirations.

\subsection{Analysis of Li Bai's Notion of Equal Communication from Cognitive Metonymic Perspective}

Although Li Bai was enthusiastic about achieving political ideals, his pride and unyielding personality bestowed upon him the notion of communicating with the nobles on equal footing, which is also highlighted through historical metonymies in his poems. The following verse is part of Song of Liang Fu, which was written in 750 $\mathrm{AD}$ after Li Bai left Chang'an.

\section{高阳酒徒起草中，}

长揖山东隆准公。

入门不拜逞雄辩,

两女辍洗来趋风。

东下齐城七十二,

指挥楚汉如旋蓬。

狂客落魄尚如此,

何况壮士当群雄! (《梁甫吟》)

Gao Yang jiu tu qi cao zhong,

Chang yi shan dong long zhun gong.

$\mathrm{Ru}$ men bu bai cheng xiong bian,

Liang nu chuo xi lai qu feng.

Dong xia qi cheng qi shi er,

Zhi hui chu han ru xuan peng.

Kuang ke luo po shang ru ci,

He kuang Zhuang shi dang qun xiong. (Liang Fu Yin)

Gaoyang drinker, a Robinhood-like figure,

Bowed with hands clasped to the high-nosed man, Liu Bang in Shangdong.

His eloquence spared him from kneeling down to Liu Bang.

Liu Bang stopped his footbath by two maids, and hurried to listen to him.

His silver tongue won seventy-two towns from Qi State,

And directed Qi and Han like floating grass.

The castaway mad man could achieve great success,

Let alone a warrior with bravery and intelligence like me.

In the above lines, Gaoyang drinker refers to Li Shiqi, who rose from underprivileged background and later became a counselor in Western Han Dynasty on the strength of his eloquence. Li Shiqi, who was rapt with wine, was known as a bohemian and maniac. The first time he visited Liu Bang, he just bowed with his hands clasped rather than kneel down. Liu Bang was conquered by his great eloquence and thought highly of him. This quotation of this historical allusion is aimed to create mental contact and association to Li Bai's own life experiences and give expression to his seeking for communicating with the monarch and the nobles as an equal.

长揖万乘君,

还归富春山。(《古风·其十二》) 
Chang yi wan sheng jun,

Huan gui fu chun shan. (Fu Feng, Qi Shi Er)

Yan Ziling bowed with hands clasped to the lord of a myriad chariots,

And retired to Fuchun Mountains after rising to prominence.

Archaic (XII) was written after Li Bai was sent away from the royal court. Guangwu (born Liu Xiu) was an emperor of the Chinese Han dynasty, restorer of the dynasty in AD 25 and thus founder of Eastern Han. As a close friend, Yan Ziling helped a lot when Liu Xiu was determined to dispatch troops for the battle to fight for the reign of the country. Having established his own kingdom, Liu Xiu very much missed his confidant, sought for him, being sincere and genuine in his wish to keep him in court. Though Liu Xiu was revered as the emperor, Yan bowed with hands clasped when they met. Though treated as a distinguished guest, Yan declined the emperor's invitation to enter political stratum and retreated to Fuchun Mountains as a recluse. The story about Yan seems to have little to do with the poet himself, which was far from true. It was said that Yang Guifei, the favorite royal consort, abetted by Gao Lishi, the most politically powerful eunuch in the palace, talked Emperor Xuanzong of Tang into driving Li Bai away from the court, with large gifts of gold and silver. This was quite discouraging and frustrating. After leaving the court, Li Bai formally became a Taoist, making a home in Shandong. Yet he still held longing for accomplishments. Therefore by the metonymy of historical allusion about Yan Ziling, the poet spoke out loud his craving for being recognized and treated by an open-minded monarch as an equal in an implicit way.

\section{Conclusion}

As a result of metonymy's less eye-catching poetic effect, its significant contribution to the creation and sustainment of complex imagery and expression of the poet's subtle feelings are all too frequently neglected in the close reading of individual texts. In other words, metonymy has long been treated as a marginal phenomenon in literary. Instead, metonymy functions as a very useful device especially in the limited space of poetry. Metonymy, is not only a rhetoric device, but also a way of thinking. That is to say, metonymy possesses the capacity to create aesthetically impressive and structurally important effects in poetry. As a cognitive device, metonymy serves as a reference point, which helps establish mental access to the target concept from the source concept. The association and interaction between the source and the target can generate far more rich connotations in poetry. This is utterly deviant from the conventional view that metonymy is just a trope in which one word is replaced by another based on some empirical associations among objects. As a matter of fact, there is nothing like a poetic equivalence between the metonymic source and the virtual metonymic target. Nor should one imagine the productive poetic process from which a metonym originates as one in which poets straight forwardly "replace", "substitute" what they "mean" by another word for the sake of superficial embellishment (Matzner, 2016, p. 65). Therefore, creative writing is considered as a process in which the poet, is reworking expressions and images over and over again and developing out of them meanings which were not the meaning he had originally wanted to express with them (Harding, 1963).

This paper investigates concrete metonymic manifestations in Li Bai's poems to figure out the metonymy and cognitive construction. It seems that the poet was telling stories about some other people in the past. Actually, he reworked these historical allusions, established connections between the allusions and his own life experience, thus developed out of them meanings, which were not literal, but the new and creative connotations he wanted to express. Historical allusions provide prompt mental access to the poet's own life from others' stories, therefore, his complicated and subtle emotions, such as his yearning for fame and success, and his notion of equal communication. Our study of actual metonymy was in part motivated by the wish to offer a reappraisal of metonymic devices in poetry from a cognitive approach as an insightful perspective for literary studies. The results demonstrate that it is productive to apply cognitive theories into the interpretation of ancient Chinese poetry since poetic metonymy is a lens to perceive the cognitive process the poet construes and thinks about the world. What' more, the poet develops the refined and derivative meaning out of ordinary language. As for the readers, the understanding of literary texts, to some degree, hinges on their mental construal of poetic metonymies although it is inarguable that cognitive construction of poetry is not just confined to metonymy. Metonymy may not embody the logical genius or the terminological sparkle of metaphor, but its greater subtlety and closer connection to ordinary usage make for a strikingly frequent employment in literary texts and a stylistic impact that is far from negligible (Matzner, 2016, p. 65). Whether in cognitive poetics or translation 
criticism, we need a sound understanding of this forgotten device, which awaits further investigation.

\section{Acknowledgments}

This article is supported by the Southwest University "Fundamental Research Funds for the Central Universities", No: SWU1209350.

\section{References}

Barcelona, A. (Ed.). (2003). Metaphor and Metonymy at the Crossroads: A Cognitive Perspective. Berlin and New York: Mouton de Gruyter. https://doi.org/10.1515/9783110894677

Esnault, G. (1925). Imagination Populaire, Metaphores Occidentales, Paris, 31. Translation by S. Ullmann, Language and Style, Oxford, 1964, 177.

Gibbs, R. (1999). Speaking and thinking with metonymy. In K.-U. Panther \& G. Radden (Eds.), Metonymy in Language and Thought (pp. 61-76). Amsterdam: John Benjamins. https://doi.org/10.1075/hcp.4.04gib

Harding. (1963). notwithstanding the explicit rhetoric of some poetic traditions, in the medieval West in particular, 101.

Lakoff, G., \& Johnson, M. (1980). Metaphors We Live by. Chicago, IL: University of Chicago Press. https://doi.org/10.1017/s0008413100023744

Langacker, R. W. (1993). Reference-point constructions. Cognitive Linguistics, 4, 1-38. https://doi.org/10.1515/cogl.1993.4.1.1

Li, C. Z. (2015). Li Bai, a Taoist Poet, and His Sorrows. Tianjin: Tianjin People's Publishing House.

Matzner, S. (2016). Rethinking Metonymy: Literary Theory and Poetic Practice from Pindar to Jakobson. Oxford: Oxford University Press. https://doi.org/10.1093/acprof:oso/9780198724278.001.0001

Pankhurst, A. (1999). Recontextualization of metonymy in narrative and the case of Morrison's Song of Solomon. In K.-U. Panther \& G. Radden (Eds.), Metonymy in Language and Thought (pp. 385-400). Amsterdam: John Benjamins. https://doi.org/10.1075/hcp.4.22pan

Radden, G., \& Kövecses, Z. (1999). Towards a theory of metonymy. In K.-U. Panther \& G. Radden (Eds.), Metonymy in Language and Thought (pp. 17-59). Amsterdam: John Benjamins. https://doi.org/10.1075/hcp.4.03rad

Radden, G., Köpcke, K.-M., Berg, T., \& Siemund, P. (2007). The construction of meaning in language. In G. Radden, K.-M. Köpcke, T. Berg, \& P. Siemund (Eds.), Aspects of Meaning Construction (pp. 1-15). Amsterdam: John Benjamins. https://doi.org/10.1075/z.136.02rad

Rosch, E. (1975). Cognitive reference point. Cognitive Psychology, 7. https://doi.org/10.1016/0010-0285(75)90021-3

Trypho. (1856). De Tropis, in Rhetores Graeci. Ed. L. Spengel. 3 vols, vol. iii. Leizpig: Teubner.

Wang, Y. X. (1989). A study on Li Bai's notion of communicating with the nobles on equal footing. Research on Li Bai in China, 1-16.

Xu, Y. C. (2000). 300 Tang Poems. Beijing: Higher Education Press.

Xu, Y. C. (2014). Selected Poems of Li Bai (translated by Xu Yuanchong). Beijing: China Translation \& Publishing Corporation.

\section{Copyrights}

Copyright for this article is retained by the author, with first publication rights granted to the journal.

This is an open-access article distributed under the terms and conditions of the Creative Commons Attribution license (http://creativecommons.org/licenses/by/4.0/). 